\title{
Characterization of Gastric Mucosal Blood Flow Response Induced by Intragastric Capsaicin in Rats
}

\author{
Jiro Matsumoto, Koji Takeuchi* and Susumu Okabe \\ Department of Applied Pharmacology, Kyoto Pharmaceutical University, \\ Misasagi, Yamashina, Kyoto 607, Japun \\ Received May 14, 1991 Accepted July 1, 1991
}

\begin{abstract}
Gastric mucosal blood flow (GMBF) was measured in the ex vivo stomachs of anesthetized rats simultaneously with mean arterial blood pressure (MBP), luminal $\mathrm{pH}$ and transmucosal potential difference $(\mathrm{PD})$ in an attempt to characterize these responses induced by capsaicin. The stomach was mounted on a Lucite chamber, perfused with saline at the flow rate of $1 \mathrm{ml} / \mathrm{min}$, and GMBF was measured by Laser flowmetry. Under these conditions, the $\mathrm{pH}, \mathrm{PD}$ and $\mathrm{GMBF}$ were 3.5 to 4.0 , -30 to $-35 \mathrm{mV}$ and $8-12 \mathrm{ml} / \mathrm{min} / 100 \mathrm{~g}$, respectively. Mucosal application of capsaicin $(0.03-1 \mathrm{mg} / \mathrm{ml}$ for $10 \mathrm{~min})$ increased $\mathrm{GMBF}$ in a concentration-dependent manner, without any change in $\mathrm{PD}, \mathrm{pH}$ and $\mathrm{MBP}$. The increased GMBF response caused by capsaicin was abolished by chemical deafferentation following systemic capsaicin injections (total dose: $100 \mathrm{mg} / \mathrm{kg}$ ), significantly attenuated by pretreatment with indomethacin $(5 \mathrm{mg} / \mathrm{kg}$, s.c. $)$ or ruthenium red $(300 \mu \mathrm{g} / \mathrm{kg}$, i.v. $)$, but was not affected by spantide ( $100 \mu \mathrm{g} / \mathrm{kg}, \mathrm{i} . \mathrm{v}$ ) ), atropine ( $300 \mu \mathrm{g} / \mathrm{kg}$, i.p.) or disodium cromoglycate (30) $\mathrm{mg} / \mathrm{kg}$, i.p.). In addition, when the mucosa was exposed to capsaicin repeatedly, this response showed a marked tachyphylaxis at a high concentration $(6 \mathrm{mg} / \mathrm{ml})$. These results suggest that intragastric capsaicin increased GMBF selectivcly through capsaicinsensitive sensory neurons, and this action may involve endogenous prostaglandins.
\end{abstract}

Capsaicin, a pungent principle of hot red pepper, is a selective stimulant of primary afferent neurons $(1-3)$. Recent studies showed that intragastric capsaicin protects the rat gastric mucosa against various ulcerogenic stimuli $(1,4)$, while chemical deafferentation by systemic capsaicin injections produces aggravation of lesions in experimental ulcer models $(1,5,6)$. However, the mechanism underlying capsaicin-induced gastric protection remains unknown.

Gastric mucosal blood flow (GMBF) is considered to play an important role in the de- fense mechanism of the gastric mucosa. In fact, several investigators reported that capsaicin produced an increase of GMBF in the rat stomach when applied intragastrically (79). Holzer et al. (10) reported that the rise in GMBF represents a primary mechanism of the mucosal protection induced by capsaicin-sensitive afferent nerve. Yet, the capsaicin action on GMBF has not been well analyzed.

In the present study, we measured GMBF in the ex-vivo stomachs of normal and sensory deafferented rats and characterized GMBF responses to intragastric application of capsaicin.

*To whom correspondence should be addressed. 


\section{MATERIALS AND METHODS}

Male Sprague Dawley rats weighing $230-$ $280 \mathrm{~g}$ (Charles River, Shizuoka, Japan) were used in all experiments. The animals were kept in individual cages with raised mesh bottoms to prevent coprophagy, and they were deprived of food but allowed free access to tap water for $18 \mathrm{hr}$ before the experiments.

\section{Experimental procedures}

The animals were anesthetized with urethane $(1.25 \mathrm{~g} / \mathrm{kg}$, i.p.), and the stomach was exposed through a midline incision and mounted on a Lucite chamber according to the previously published method (11). Under these conditions, the mucosa was perfused at a flow rate of $1 \mathrm{ml} / \mathrm{min}$ with saline $(154 \mathrm{mM}$ $\mathrm{NaCl}, 37^{\circ} \mathrm{C}$ ); the $\mathrm{pH}$ of gastric effluent was measured by a $\mathrm{pH}$ glass electrode of the flow type (Horiba Model 6901-25T); and the transmucosal potential difference (PD) was determined using two agar bridges, one positioned in the chamber and the other in the abdominal cavity. Changes in PD were continuously monitored on a recorder (Nippon Densi Kagaku, Model U-228) simultaneously with those in pH. GMBF was measured by laser Doppler flowmetry (Advance, Model ALF-2100) and by softly touching the probe $(1 \mathrm{~mm}$ in diameter) on the surface of the corpus mucosa, while the mean arterial blood pressure (MBP) was monitored via the femoral artery by a blood pressure transducer and amplifier system (San-ei, Type 45277; Type 1829). After all parameters had well-stabilized, the perfusion was discontinued; the luminal solution was removed; and then the mucosa was exposed for $10 \mathrm{~min}$ to $2 \mathrm{ml}$ of capsaicin. After application, the mucosa was rinsed with saline, another 2 $\mathrm{ml}$ of saline instilled, and the perfusion resumed. Monitoring of $\mathrm{pH}$ was interrupted for 10 min while the mucosa was exposed to capsaicin, whereas the other parameters were continuously monitored during a $2 \mathrm{hr}$-test period. In some experiments, the mucosa was expose for $10 \mathrm{~min}$ to capsaicin repeatedly at 90 -min intervals. In separate experiments, the effects of chemical deafferentation and various drugs on the GMBF response induced by capsaicin were examined. Chemical deafferetation was performed 2 weeks before the experiment by consecutive injections of capsaicin subcutanenously once daily for 3 days $(20,30$, and $50 \mathrm{mg} / \mathrm{kg}$ ) (12). All capsaicin injections were performed under ether anesthesia, and the rats were pretreated with terbutaline $(0.1$ $\mathrm{mg} / \mathrm{kg}$, i.m.) and aminophylline $(10 \mathrm{mg} / \mathrm{kg}$, i.m.) to counteract the respiratory impairment associated with capsaicin injection. The effectiveness of the treatment was tested by examining the protective wiping movment of the cye (13). On the other hand, disodium cromoglycate (DSCG: $30 \mathrm{mg} / \mathrm{kg}$, i.p.), a mast cell stabilizer (14); atropine $(300 \mu \mathrm{g} / \mathrm{kg})$, a muscarinic antagonist; and indomethacin (5 $\mathrm{mg} / \mathrm{kg}$, s.c.), a cyclooxygenase inhibitor (15) were given $30 \mathrm{~min}$ before mucosal application of capsaicin, while spantide $(100 \mu \mathrm{g} / \mathrm{kg}$, i.v. $)$, a substance $P$ antagonist, and ruthenium red ( $300 \mu \mathrm{g} / \mathrm{kg}$, i.v.), a functional antagonist of capsaicin for stimulation of primary afferent neurons (16), were given $10 \mathrm{~min}$ before capsaicin treatment.

\section{Preparations and drugs used}

Urethane (Tokyo Kasei, Japan), capsaicin (Wako, Japan), ruthenium red (Wako), indomethacin (Sigma Chemicals, U.S.A.), atropine (Sigma Chemicals), aminophylline

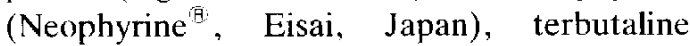
(Bricanyl $^{\text {B' }}$, Fujisawa, Japan), disodium cromoglycate (Fisons, England) and spantide (Peptide Institute, Japan). Capsaicin was dissolved in Tween 80-ethanol solution (10\% ethanol, $10 \%$ Tween 80 and $80 \%$ saline) (13) for s.c. injection and was suspended in $0.5 \%$ carboxymethylcellulose solution (CMC) for mucosal application. DSCG, spantide and ruthenium red were dissolved in saline. Indomethacin was suspended in saline with a drop of Tween 80. Each drug was prepared immediately before use and was given in a volume of $0.5 \mathrm{ml} / 100 \mathrm{~g}$ of body wt. in the case of i.p. and s.c. administration or in a volume of $0.1 \mathrm{ml} / 100 \mathrm{~g}$ of body wt. in case of i.v. 
administration. Control animals received the vehicle alone.

\section{Statistics}

The data are presented as the means \pm S.E. from 4-7 rats per group. Statistical analyses were performed using the two-tailed Dunnett's multiple comparison test (17) and values of $\mathrm{P}<0.05$ were regarded as significant.

\section{RESULTS}

Effects of capsaicin on $p H, P D$ and $G M B F$ in the stomach

The gastric mucosa mounted in a Lucite chamber generated a PD of about -30 to $-35 \mathrm{mV}$, secreted acid to keep the luminal $\mathrm{pH}$ of about 3.5-4.0, and maintained a GMBF of about $6-15 \mathrm{ml} / \mathrm{min} / 100 \mathrm{~g}$ (Fig. 1). These values remained relatively constant during a 2-hr test period and were not significantly changed after mucosal application of $0.5 \%$ CMC solution. Under these conditions, the exposure of the mucosa to capsaicin (0.01-1 $\mathrm{mg} / \mathrm{ml}$ ) for $10 \mathrm{~min}$ did not produce any significant change on either $\mathrm{pH}, \mathrm{PD}$ or MBP, but the mucosa responded to capsaicin by a concentration-related increase of GMBF; a significant effect was observed at $0.03 \mathrm{mg} / \mathrm{ml}$ or greater (Figs. 1 and 2). The magnitude of the GMBF response caused by capsaicin reached the maximal values at the concentration of $0.1 \mathrm{mg} / \mathrm{ml}$, showing about a $63 \%$ increase over the basal values, but the duration of this response became much longer when the concentration was increased. At $1 \mathrm{mg} / \mathrm{ml}$ of capsaicin, the GMBF was increased by $66 \%$ and remained elevated for more than $1 \mathrm{hr}$.

The increase of GMBF induced by capsaicin was totally attenuated in the animals following chemical deafferentation by consecutive injections of capsaicin 2 weeks before the experiment (Fig. 2). In these animals, the GMBF remained unchanged before, during and after exposure of the mucosa to capsaicin $(0.1$ $\mathrm{mg} / \mathrm{ml}$ ). Similar phenomenon was observed in the animals where the mucosa was exposed repeatedly to a high concentration of capsaicin. As shown in Fig. 3, the mucosa responded to the first application of capsaicin $(6 \mathrm{mg} / \mathrm{ml})$ by a marked and persistent increase of GMBF $(72.4 \pm 21.5 \%)$ but showed the minimal re-
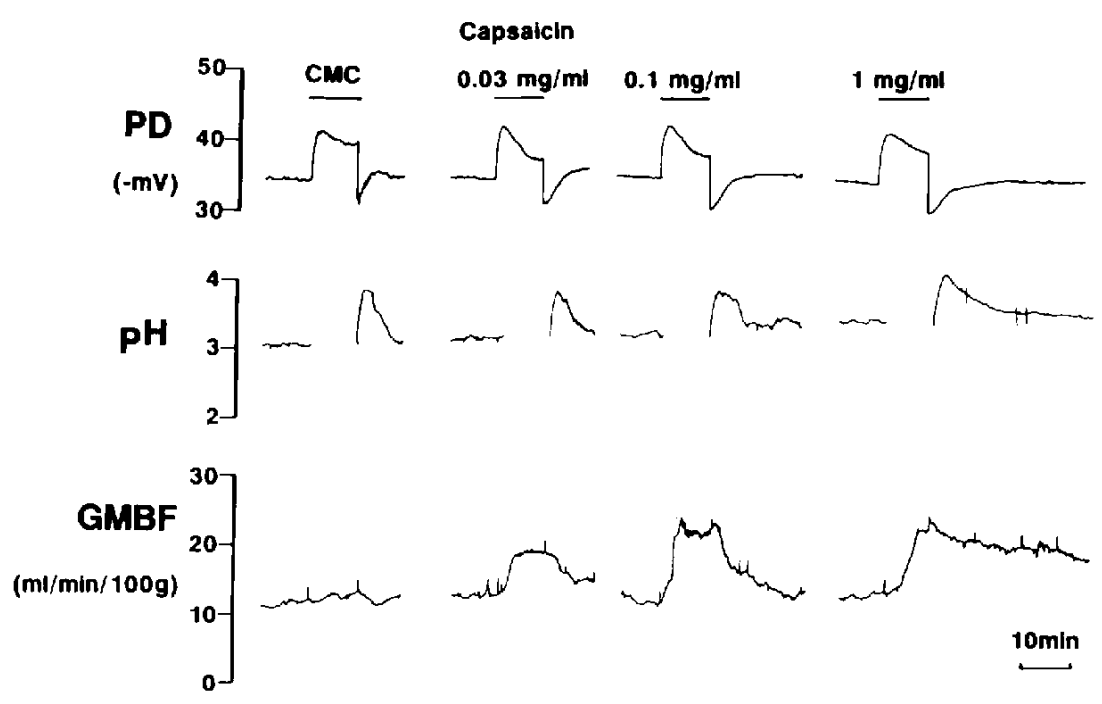

Fig. 1. Representative recording showing the effects of various concentrations of capsaicin on the transmucosal potential difference (PD), $\mathrm{pH}$ and gastric mucosal blood flow (GMBF) in the ex vivo stomach of anesthetized rat. Capsaicin $(0.03-1 \mathrm{mg} / \mathrm{ml})$ was applied topically to the mucosa for $10 \mathrm{~min}$. 


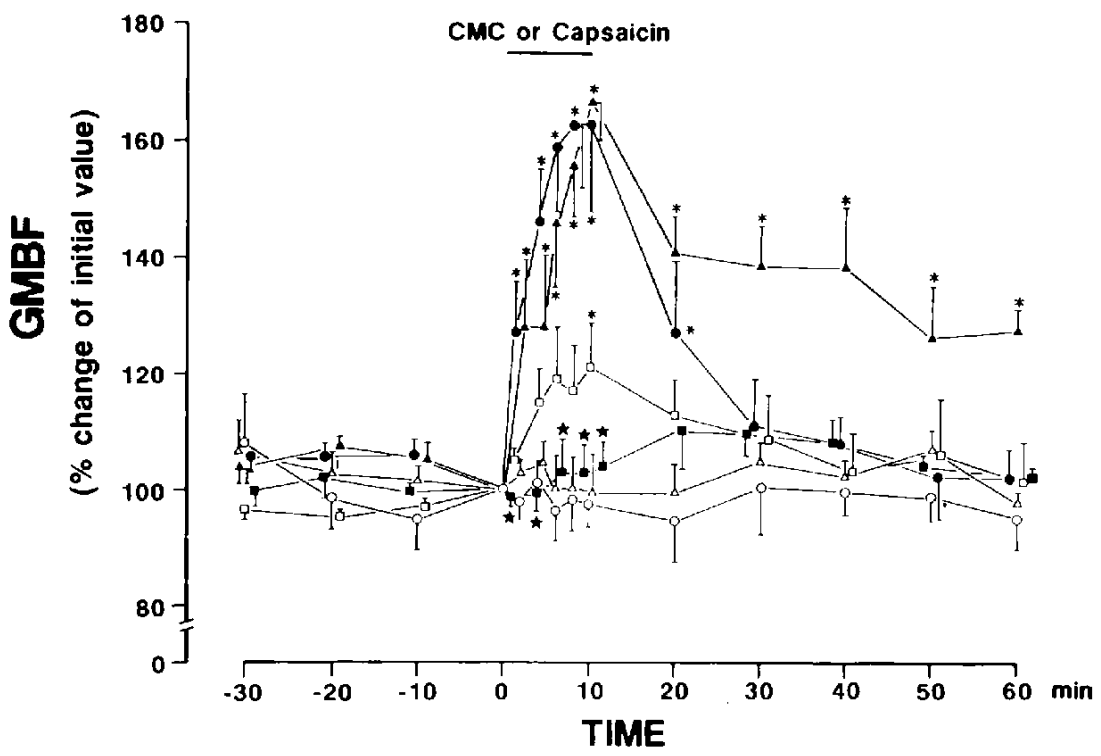

Fig. 2. Effects of mucosal application of capsaicin on gastric mucosal blood flow (GMBF) in the ex vivo stomachs of anesthetized rats and its reversal by chemical deafferentation. Capsaicin $(0.01-1 \mathrm{mg} / \mathrm{ml}) \mathrm{was}$ topically applied to the mucosa for $10 \mathrm{~min}$, and the stomach was perfused with saline before and after the application. Chemical deafferentation (capsaicin pretreatment) was performed 2 weeks before the experiment by consecutive injections of capsaicin s.c. once daily for 3 days (total dose: $100 \mathrm{mg} / \mathrm{kg}$ ). The data are expressed as \% increase of basal values and represent the means \pm S.E. of values determined every 2 or 10 min from 4-7 rats. Statistically significant difference at $\mathrm{P}<0.05:{ }^{*}$ from the control group (CMC), ${ }^{\star}$ from the group treated with capsaicin $(0.1 \mathrm{mg} / \mathrm{ml})$ alone. $\bigcirc:$ control (CMC), $\triangle$ : capsaicin, $0.01 \mathrm{mg} / \mathrm{ml}, \square: \mathrm{cap}-$ saicin, $0.03 \mathrm{mg} / \mathrm{ml}$, capsaicin, $0.1 \mathrm{mg} / \mathrm{ml}$, $\Delta$ : capsaicin, $1.0 \mathrm{mg} / \mathrm{ml}$, $\mathbf{0}$ : capsaicin pretreatment + capsaicin, $0.1 \mathrm{mg} / \mathrm{ml}$.

sponses after the second application of capsaicin at the same concentration, the degree of increase being $6.1 \pm 2.6 \%$.

Effects of various agents on GMBF response induced by mucosal application of capsaicin

Since the capsaicin effect on GMBF reached the maximal values $(\sim 70 \%$ increase over the basel values) at $0.1 \mathrm{mg} / \mathrm{ml}$, this concentration was used in the following experiments for examining the effects of various agents on the GMBF response to capsaicin. By exposure of the mucosa to $0.1 \mathrm{mg} / \mathrm{ml}$ of capsaicin for 10 min, the GMBF increased from $11.9 \pm 0.8$ $\mathrm{ml} / \mathrm{min} / 100 \mathrm{~g}$ to the maximal values of $21.3 \pm$ $1.5 \mathrm{ml} / \mathrm{min} / 100 \mathrm{~g}(79 \%$ increase over the basal values). Treatment of the animals with DSCG, atropine, spantide, or indomethacin by itself did not significantly affect GMBF as well as
$\mathrm{pH}$ and PD (not shown), while the GMBF showed a transient increase immediately after i.v. injection of ruthenium red, followed by a return to the baseline values within $10 \mathrm{~min}$. However, the increased GMBF response caused by capsaicin was significantly attenuated by either indomethacin $(5 \mathrm{mg} / \mathrm{kg}$, s.c.) or ruthenium red $(300 \mu \mathrm{g} / \mathrm{kg}$, i.v.), the degree of inhibition being $80.6 \%$ or $92.7 \%$, respectively (Figs. 4 and 5). Although spantide $(100 \mu \mathrm{g} /$ $\mathrm{kg}$, i.v.) showed a slight inhibition on the GMBF response to capsaicin, the degree of increase observed in the presence of this agent was not significantly different when compared to the control. Pretreatment of the animals with DSCG $(30 \mathrm{mg} / \mathrm{kg}$, i.p.) or atropine $(300$ $\mu \mathrm{g} / \mathrm{kg}$, i.p.) had no effect on the increase of GMBF in response to capsaicin. 


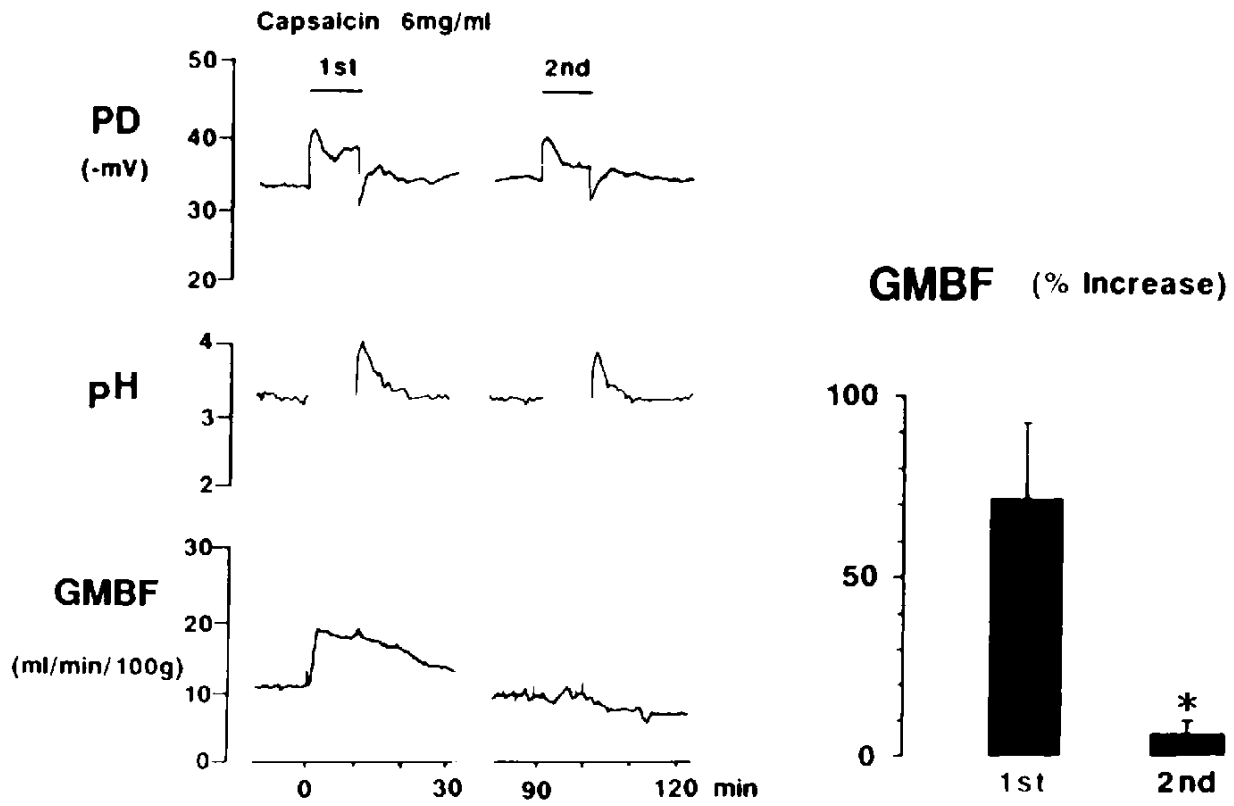

Fig. 3. Effects of repeated application of capsaicin on the transmucosal pontential difference (PD), pH and gastric mucosal blood flow (GMBF) in the ex vivo stomachs of anesthetized rats (left panel: representative recordings of $\mathrm{PD}, \mathrm{pH}$ and GMBF; right panel: quantitative data for GMBF). The gastric mucosa was exposed for $10 \mathrm{~min}$ to capsaicin $(6 \mathrm{mg} / \mathrm{ml})$ repeatedly at 90 -min intervals in the same animals. The data in GMBF are expressed as $\%$ increase of basal values and represent the means $\pm \mathrm{S}$. E. from 6 rats. ${ }^{*}$ Statistically significant difference from the values observed after the first application, at $\mathrm{P}<0.05$.

\section{DISCUSSION}

Capsaicin-sensitive sensory neurons are considered to play an important role in the pathophysiology of the gastric mucosa, being involved in actions such as changes in acid secretion and motility $(7,18,19)$, blood flow regulation $(7-9,20)$ or the maintenance of the mucosal integrity against irritants $(4,5,10$, 12). The present study confirmed that mucosal application of capsaicin produced an increase of GMBF in the rat stomach and further showed that this effect was blocked by indomethacin as well as chemical deafferentation following capsaicin pretreatment, suggesting involvement of endogenous prostaglandins (PGs) in the GMBF response to stimulation of capsaicin-sensitive sensory neurons.

In the present study, the effects of capsaicin on GMBF were examined simultaneously with those on luminal $\mathrm{pH}$ and transmucosal $\mathrm{PD}$ in the ex-vivo stomach mounted in a Lucite chamber. Mucosal application of capsaicin produced a concentration-related increase of GMBF, but did not significantly affect either $\mathrm{pH}, \mathrm{PD}$ or MBP. We previously reported that monitoring of $\mathrm{pH}$ and $\mathrm{PD}$ in this system represents changes in acid secretion and integrity of the gastric mucosa, respectively (11). The finding that capsaicin had no effect on luminal $\mathrm{pH}$ is consistent with the recent observation by Esplugues et al. (18) who showed that capsaicin did not significantly affect basal acid secretion. On the other hand, mucosal application of mild irritants such $20 \%$ ethanol or $1 \mathrm{M} \mathrm{NaCl}$ also increased GMBF in the rat stomach but these effects were accompanied by a marked PD reduction and surface epithelial damages $(8,21,22)$. Capsaicin did not act on the stomach as a mild irritant, inasmuch as this agent did not produce any histological damage in the gastric mucosa and had no 


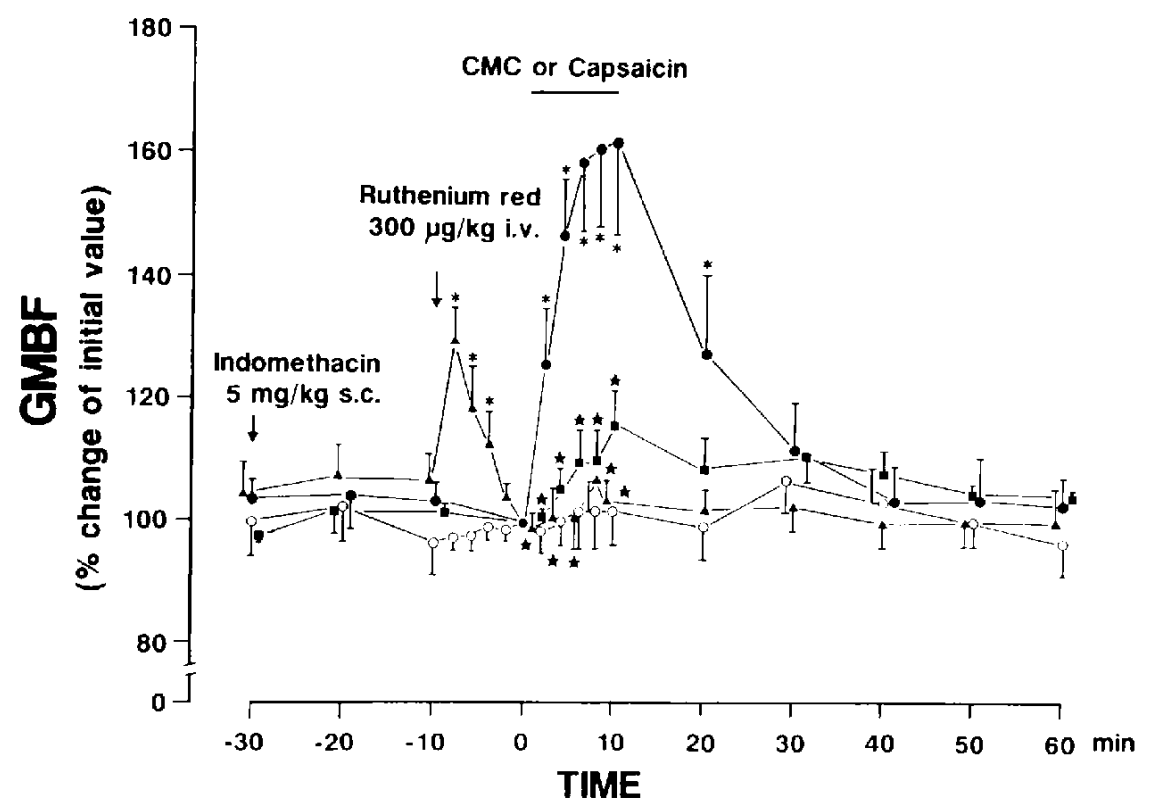

Fig. 4. Effects of indomethacin and ruthenium red on the increased gastric mucosal blood flow (GMBF) response induced by capsaicin in the ex vivo stomachs of anesthetized rats. Capsaicin $(0.1 \mathrm{mg} / \mathrm{ml})$ was applied topically to the mucosa for $10 \mathrm{~min}$. Indomethacin $(5 \mathrm{mg} / \mathrm{kg}, \mathrm{s} . \mathrm{c}$.) or ruthenium $\mathrm{red}(300 \mu \mathrm{g} / \mathrm{kg}, \mathrm{i} . \mathrm{v}$.) was given $30 \mathrm{~min}$ or $10 \mathrm{~min}$ before capsaicin application, respectively. The data are expressed as $\%$ increase of basal values and represent the means $\pm S$. E. of values determined every 2 or $10 \mathrm{~min}$ from $6-7$ rats. Statistically significant difference at $\mathbf{P}<0.05:{ }^{*}$ from the control group (CMC), from the group treated with capsaicin alone. $O$ : control (CMC). 0 : capsaicin, $0.1 \mathrm{mg} / \mathrm{ml}, \mathbf{Q}$ : indomethacin pretreatment + capsaicin, $0.1 \mathrm{mg} / \mathrm{ml}, \boldsymbol{\Delta}$ : ruthenium red pretreatment + capsaicin, $0.1 \mathrm{mg} / \mathrm{ml}$.

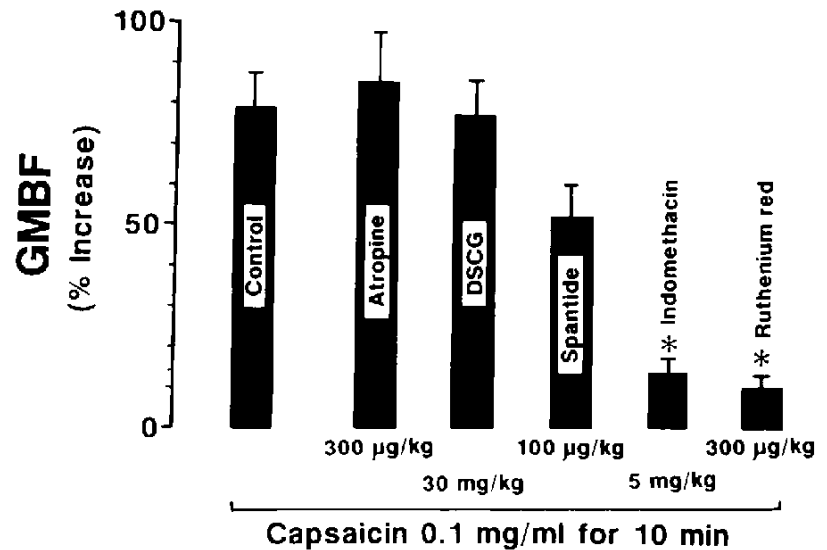

Fig. 5. Effects of various agents on the gastric mucosal blood flow (GMBF) response induced by capsaicin in the ex vivo stomachs of anesthetized rats. Capsaicin $(0.1 \mathrm{mg} / \mathrm{ml})$ was applied topically to the mucosa for $10 \mathrm{~min}$. Indomethacin ( $5 \mathrm{mg} / \mathrm{kg}$, s.c.), DSCG $(30 \mathrm{mg} / \mathrm{kg}$, i.p.) or atropine $(300 \mu \mathrm{g} / \mathrm{kg}$, i.p.) was given 30 min before application of capsaicin, while spantide $(100 \mu \mathrm{g} / \mathrm{kg}$, i.v. $)$ or rethenium red $(300 \mu \mathrm{g} / \mathrm{kg}$, i.v.) was given $10 \mathrm{~min}$ before capsaicin treatment. The data are expressed as \% increase of basal values and represent the means \pm S.E. from 5-7 rats. ${ }^{*}$ Statistically significant difference from the control, at $\mathrm{P}<0.05$. 
effect on PD $(8,19)$. Thus, it seems likely that capsaicin action on GMBF is independent from acid secretory changes and does not result from the barrier disruption.

The increased GMBF response caused by capsaicin was almost totally attenuated by chemical deafferentation following consecutive injections of capsaicin 2 weeks before the experiment, suggesting that this action is mediated by capsaicin-sensitive sensory nerves. This contention is also supported by the following observations that the capsaicin action on GMBF was inhibited by prior administration of ruthenium red and showed a marked tachyphylaxis after the repeated application at a high concentration $(6 \mathrm{mg} / \mathrm{ml})$. The former result can be explained on the basis of the previous finding that ruthenium red functionally antagonizes the action of capsaicin on the peripheral terminals of sensory neurons and inhibits the release of transmitter from capsaicin-sensitive afferent neurons $(23,24)$. The transient increase in GMBF seen after administration of ruthenium red may be due to the vascular response to this agent. On the other hand, the latter observation may be $c x-$ plained by desensitization of the sensory neurons to capsaicin, probably because of insufficient release of neurotransmitter in the capsaicin-sensitive sensory neurons. In fact, several investigators reported a similar phenomenon in various actions of capsaicin such as neuropeptide release in the urinary bladder (24), contraction of smooth muscle of various tissues $(23,24)$ or alkaline secretory response in the duodenum (25).

Capsaicin exerts a potent excitatory effect on the nerve ending of sensory neurons and results in the release of a vasodilating transmitter(s) such as calcitonin-gene related peptide (CGRP), substance $P$ or vasoactive intestinal peptide (VIP) (26). In the gastrointestinal mucosa, mast cells have been shown to be opposed to substance $P$ containing nerve endings, and substance $\mathrm{P}$ has been shown to stimulate release of histamine from mast cells (27). In this study, spantide (a substance $P$ antagonist) and DSCG (a mast cell stabilizer) did not significantly affect the increase of GMBF induced by capsaicin. The former agent at $10 \mu \mathrm{g} / \mathrm{kg}$, i.v. inhibited the gastric contractile response induced by substance $\mathrm{P}$ or that mediated by capsaicin-sensitive afferent neurons in the vagus nerves in rats (personal communication from $\mathrm{H}$. Kitagawa), suggesting that the dose used $(100 \mu \mathrm{g} / \mathrm{kg}$, i.v. $)$ is sufficient for testing substance $P$ involvement in the capsaicin-induced GMBF response. A slight suppression of the GMBF response by spantide may be due to the non-specific action of this agent on the vasculature, because spantide alone at higher doses decreased GMBF significantly (unpublished data, J. Matsumoto et al.). These results may suggest that substance $\mathrm{P}$ is not the neurotransmitter responsible for the increase of GMBF seen after exposure to capsaicin. In fact, a recent study showed that CGRP may be a possible mediator for the GMBF response to stimulation of capsaicinsensitive sensory neurons (20). Failure of atropine to affect the GMBF response agrees with the observation that the cytoprotective action of capsaicin was not influenced by either atropine or hexamethonium and had no interaction with cholinergic nerves (4). These results, however, suggest that the capsaicin effects on various functions are mediated by different mechanisms, since we recently found that the $\mathrm{HCO}_{3}{ }^{-}$stimulatory action of capsaicin was significantly suppressed by atropine in the rat duodenum (25).

Of interest, the increased GMBF response induced by capsaicin was significantly suppressed by indomethacin, a cyclooxygenase inhibitor, the finding being consistent with our recent observation that the cytoprotective action of capsaicin was significantly attenuated by indomethacin as well as chemical deafferentation (19). However, this result disagrees with the previous observation by others $(5,10)$ that intragastric capsaicin did not alter the ex vivo formation of $\mathrm{PGE}_{2}$ in the gastric mucosa. $\mathrm{PGs}$ locally generated by tissue trauma have long been recognized as activating nociceptive afferent neurons $(13,28)$. It might be possible that endogenous PGs sensitize the afferent 
neurons to stimulation by capsaicin, resulting in potentiation of the GMBF response mediated by capsaicin-sensitive sensory neurons. Further study should be required to prove that PGs are involved in the GMBF responses induced by stimulation of capsaicin-sensitive sensory nerves.

Taken together, the present study showed that mucosal application of capsaicin increased GMBF in the rat stomach by stimulating primary afferent neurons within the gastric mucosa. At the present stage of research, although the mechanism of capsaicin-induced GMBF response remains still unclear at the neurotransmitter levels, it became evident that this action needs endogenous PGs for its appearance but is not related to substance $P$ or mast cell mediators which may be released by substance $P$.

\section{REFERENCES}

1 Szolcsanyi, J. and Bartho, L.: Impaired defense mechanism to peptic ulcer in the capsaicin-desensitized rat. In Gastrointestinal Defense Mechanisms, Edited by Mozik, Gy., Hanninen, $O$. and Javor, T., Advances in Physiological Science, p. 39-51, Pergamon Press and Akademiaki Kiado, Oxford and Budapest (1981)

2 Russell, L.C. and Burchiel, K.J.: Neurophysiological effects of capsaicin. Brain Res. Rev. 8, $165-176$ (1984)

3 Buck, S.H. and Burks, T.F.: The neuropharmacology of capsaicin: review of some recent observations. Pharmacol. Rev. 38, 179-226 (1986)

4 Holzer, P. and Lippe, I.Th.: Stimulation of afferent nerve endings by intragastric capsaicin protects against ethanol-induced damage of gastric mucosa. Neuroscience 27, 981 - 987 (1988)

5 Holzer, P. and Sametz, W.: Gastric mucosal protection against ulcerogenic factors in the rat mediated by capsaicin-sensitive afferent neurons. Gastroenterology 91, 975-981 (1986)

6 Evangelista, S., Maggi, C.A. and Meli, A.: Involvement of capsaicin-sensitive mechanism(s) in the antiulcer defence of intestinal mucosa in rats. Proc. Soc. Exp. Biol. Med. 184, 264-266 (1987)

7 Lippe, I.Th., Pabst, M.A. and Holzer, P.: Intragastric capsaicin enhances rat gastric acid elimination and mucosal blood flow by afferent nerve stimulation. Br. J. Pharmacol. 96, 91 - 100 (1989)
8 Matsumoto, J., Ueshima, K., Takeuchi, K. and Okabc, S.: Rolc of Capsaicin-sensitive afferent nerves in adaptive responses of the rat stomach to a mild irritant. Japan. J. Pharmacol. 55, 181-185 (1991)

9 Matsumoto, J., Ueshima, K., Takeuchi, K. and Okabe, S.: Functional alterations associated with gastric cytoprotection induced by capsaicin. Japan. J. Pharmacol. 55, Supp. 1, 386P (1991)

10 Holzcr, P., Pabst, M.A., Lippe, I.Th., Peskar, B.A., Livingston, E.H. and Guth, P.H.: Afferent nerve-mediated protection against deep mucosal damage in the rat stomach. Gastroenteorlogy 98 , $838-848(1990)$

11 Takeuchi, K., Ishihara, Y., Okada, M., Niida, H. and Okabe, S.: A continuous monitoring of mucosal integrity and secretory activity in rat stomach: a preparation using a lucite chamber. Japan. J. Pharmacol. 49, 235-244 (1989)

12 Esplugeus, J.V. and Whittle, B.J.R.: Morphine potentiation of ethanol-induced gastric mucosal damage in the rat: role of local sensory afferent neurons. Gastroenterology 98, 82-89 (1990)

13 Yonei, Y., Holzer, P. and Guth, P.H.: Laparotomy-induced gastric protection against ethanol injury is mediated by capsaicin-sensitive sensory neurons. Gastroenterology 99, 3-9 (1990)

14 Orr, T.S.C., Hall, D.E., Gwilliam, J.M. and Cox, J.S.G.: The effect of disodium cromoglycate on the release of histamine and degranulation of rat mast cells induced by compound 48/80. Life Sci. 10, 805-812 (1971)

15 Whittle, B.J.R., Higgs, G.A., Eakins, K.E., Moncada, S. and Vane, J.R.: Selective inhibition of prostaglandin production in inflammatory exudates and gastric mucosa. Nature 284, 271-273 (1980)

16 Amann, R. and Lembeck, F.: Ruthenium red selectively prevents capsaicin-induced nociceptor stimulation. Eur. J. Pharmacol. 161, 227-229 (1989)

17 Dunnett, C.W.: A multiple comparison procedure for comparing several treatments with a control. J. Am. Stat. Assoc. 50, 1096-1121 (1955)

18 Esplugues, J.V., Ramos, E.G., Gil, L. and Esplugues, J.: Influence of capsaicin-sensitive afferent neurons on the acid secretory responses of the rat stomach in vivo. Br. J. Pharmacol. 100, $491-496(1990)$

19 Takeuchi, K., Niida, H., Matsumoto, J., Ueshima, K. and Okabe, S.: Gastric motility changes in capsaicin-induced cytoprotection in the rat. Japan. J. Pharmacol. 55, 147-155 (1991)

20 Holzer, P., Tache, Y. and Guth, P.H.: The vaso- 
dilator ncuropeptides, $\alpha$-CGRP and VIP, but not substance $P$ and neurokinin $A$, increase rat gastric mucosal blood flow (abstract). Gastroenterology 98, A-175 (1990)

21 Takeuchi, K., Yamakuni, H., Nobuhara, Y, and Okabe, S.: Functional and morphological alterations in the rat stomach following exposure to hypertonic $\mathrm{NaCl}$ solution. Japan. J. Pharmacol. 42, $549-557$ (1986)

22 Takeuchi, K., Ohno, T. and Okabe, S.: Initative and protective activity of mild irritants in rat stomach. Dig. Dis. Sci. 32, 889-896 (1987)

23 Maggi, C.A., Santicioli, P., Geppetti, P., Parlani, M., Astolfi, M., Pradelles, P., Patacchini, R. and Meli, A.: The antagonism induced by ruthenium red of the actions of capsaicin on the peripheral terminals of sensory neurons: further studies. Eur. J. Pharmacol. 154, 1-10 (1988)

24 Maggi, C.A. and Meli, A.: The sensory-efferent functions of capsaicin-sensitive sensory neurons.
Gen. Pharmacol. 19, 1-43 (1988)

25 Takeuchi, K., Matsumoto, J., Ueshima, K. and Okabe, S.: Role of capsaicin-sensitive afferent neurons in alkaline secretory response to luminal acid in the rat duodenum. Gastroenterology (in press)

26 Holzer, P.: Local effector functions of capsaicinsensitive sensory nerve endings: involvement of tachykinins, calcitonin gene-related peptide and other neuropeptides. Neuroscience 24, 739-768 (1988)

27 Stcad, R.H., Dixon, M.F., Bramwell, N.H., Riddel, R.H. and Bienenstock, J.: Mast cells are closely opposed to nerves in the human gastrointestinal mucosa. Gastroenterology 97, 575-581 (1989)

28 Lundberg, J.M. and Saria, A.: Polypeptide-containing neurons in airway smooth muscle. Annu. Rev. Physiol. 49, 557 - 572 (1987) 